The Open Civil Engineering Journal
CrossMark
Content list available at: www.benthamopen.com/TOCIEJ/
DOI: $10.2174 / 1874149501711010244$

RESEARCH ARTICLE

\title{
Experiment and Design Method on Cold-Formed Thin-Walled Steel Lipped Channel Columns with Slotted Web Holes Under Axial Compression
}

\author{
Xingyou $\mathrm{Yao}^{1,2, *}$ \\ Security, Nanchang, Jiangxi, 330099, P.R. China \\ ${ }^{2}$ Tongji University, Department of building Engineering, Shanghai, 200092, P.R. China
}

${ }^{I}$ Nanchang Institute of Technology, Jiangxi Province Key Laboratory of Hydraulic and Civil Engineering Infrastructure

Received: November 10, 2016

Revised: February 11, 2017

Accepted: February 23, 2017

\begin{abstract}
:
Background:

Cold-formed steel structural sections used in the walls of residential buildings and agricultural facilities are commonly C-shaped sections with web holes. These holes located in the web of sections can alter the elastic stiffness and the ultimate strength of a structural member. The objective of this paper is to study the buckling mode and load-carrying capacity of cold-formed thin-walled steel column with slotted web holes.
\end{abstract}

\section{Methods:}

Compression tests were conducted on 26 intermediate length columns with and without holes. The tested compressive members included four different kinds of holes. For each specimen, a shell finite element Eigen-buckling analysis and nonlinear analysis were also conducted. The influence of the slotted web hole on local and distortional buckling response had also been studied. The comparison on ultimate strength between test results and calculated results using Chinese cold-formed steel specification GB50018-2002, North American cold-formed steel specification AISI S100-2016, and nonlinear Finite Element method was made.

Result:

Test results showed that the distortional buckling occurred for intermediate columns with slotted holes and the ultimate strength of columns with holes was less than that of columns without holes. The ultimate strength of columns decreased with the increase in transverse width of hole in the cross-section of member. The Finite element analysis results showed that the web holes could influence on the elastic buckling stress of columns. The shell finite element could be used to model the buckling modes and analysis the ultimate strength of members with slotted web holes. The calculated ultimate strength shows that results predicted with AISI S100-2016 and analyzed using finite element method are close to test results. The calculated results using Chinese code are higher than the test results because Chinese code has no provision to calculate the ultimate strength of members with slotted web holes.

\section{Conclusion:}

The calculated method for cold-formed thin-walled steel columns with slotted web holes are proposed based on effective width method in Chinese code. The results calculated using the proposed method show good agreement with test results and can be used in engineering design for some specific cold-formed steel columns with slotted web holes studied in this paper.

Keyword: Axially-compressive members, cold-formed steel, effective width method, slotted hole, buckling, thin walled steel

\footnotetext{
* Address correspondence to this author at Nanchang Institute of Technology, Jiangxi Province Key Laboratory of Hydraulic and Civil Engineering Infrastructure Security, Nanchang, Jiangxi, 330099, P.R. China; Tel:+86-15079190103; E-mail: yaoxingyoujd@163.com
} 


\section{INTRODUCTION}

Cold-formed steel structural sections used in the walls of residential buildings and agricultural facilities are commonly C-shaped sections with web holes. These holes located in the web of sections can alter the elastic stiffness and the ultimate strength of a structural member [1]. The stud columns with holes tests were conducted [2-8] and the type, location, and dimension of holes were taken into account. Stub column tests [2] demonstrated that the ultimate strength decreased as the diameter of circular hole increased relative to the web width. Similar conclusions have also been reported when the influence of circular, slotted, and rectangular web holes on stub column ultimate strength was studied [3 - 5]. The impact of the location of the hole in the stub column and the length of the hole [6 - 8] has also been studied. Based on these studies, the effect width method for the ultimate strength of members with holes was developed considering local buckling and yielding strength. This design method is used in North American cold-formed steel specification [9]. In recent years, the elastic buckling performance and Direct Strength Method (DSM) of columns with holes were studied by Moen and Schafer [10 - 13]. The elastic buckling analysis of plate with holes under axial compression and bending [10] demonstrated that holes might create unique buckling modes, and could either decrease or increase a plate's critical elastic buckling stress depending on the hole's geometry and spacing. Based on the elastic buckling analysis of cold-formed steel columns and beams with holes [11], the calculated methods for elastic global, distortional and local buckling strength of a cold-formed steel member with holes under axial compression and bending have been put forward. The short and intermediate length stud columns with holes tests were conducted [12] and the experiments showed that slotted web holes have a minimal influence on the tested ultimate strength in the specimens considered. Direct strength design methods for cold-formed columns and beams with holes have been reported [13] and incorporated in North American cold-formed steel specification [9]. These researches indicated that the web holes might modify the local and distortional elastic buckling half-wavelengths, change the critical elastic buckling strength, and decrease the ultimate strength and the post-peak ductility in some cases.

The test and finite element analysis of cold-formed steel columns with holes [14] demonstrated that the ultimate strength would decrease if the hole was in the range of effective width of the element. The equivalent modulus method was developed to predict the critical buckling stress of axially compressive columns with web and flange holes [15]. An equivalent volume method was proposed to consider the effect of holes based on the test and theoretical analysis [16]. While these researches did not develop a reasonable calculated method in consistent with Chinese cold-formed steel specification (GB50018-2002) [17] to predict the ultimate strength of cold-formed steel members with slotted holes.

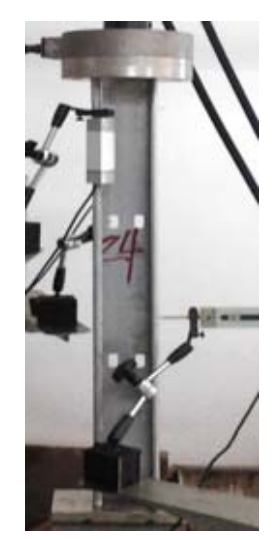

Fig. (1). Overall view of test setup.

The aim of this experiment is to expand the existing columns data, especially for columns with multiple slotted web holes. The buckling mode and ultimate strength are analyzed using Finite Element Method. The proposed design method of the ultimate strength for specific cold-formed steel columns with multiple slotted web holes is put forward based on Chinese cold-formed steel specification.

\section{EXPERIMENTAL SETUP AND SPECIMENS}

\subsection{Test Set-up}

Twenty-six cold-formed steel lipped channel columns with and without slotted web holes were tested to failure. The 
overall view of axially-compressed columns tests arrangement is shown in Fig. (1). -The column specimens bear directly to the steel plates to simulate the fixed-fixed support. The columns compression tests were performed with $200 \mathrm{kN}$ hydraulic jack testing machine. Near the $90 \%$ ultimate strength, the static load was paused for half minute and loaded again. This allowed the stress relaxation with the occurrence of the plastics. A data acquisition system was used to record the displacement and load during the tests. Displacement control was adopted to drive the hydraulic actuator a constant rate of $0.3 \mathrm{~mm} / \mathrm{min}$ for the axially-compressed tests. Three displacement transducers were positioned at the flange and web to measure the distortional buckling and local buckling. One transducer was positioned at the top support plate to record the vertical displacement of specimen.

\subsection{Hole Type and Locations}

The four kinds of slotted web hole types Fig. (2) are selected to test for the axially compressed members, where the location of holes for the specimens with one row holes is at the mid-height of the columns, and the location of holes for the specimens with two rows holes is at the $1 / 3$ and 2/3 height of the columns. The nominal length $\left(L_{\mathrm{h}}\right)$ and width $\left(H_{\mathrm{h}}\right)$ of the slotted hole are $25 \mathrm{~mm}$ and $14 \mathrm{~mm}$ and the nominal vertical $\left(S_{1}\right)$ and transverse $\left(S_{2}\right)$ distance of holes are 250 and $50 \mathrm{~mm}$.

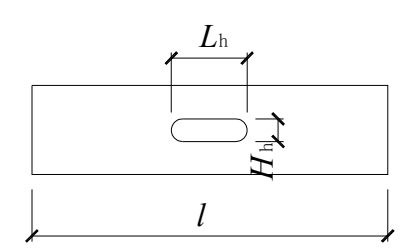

(a) One hole in one row

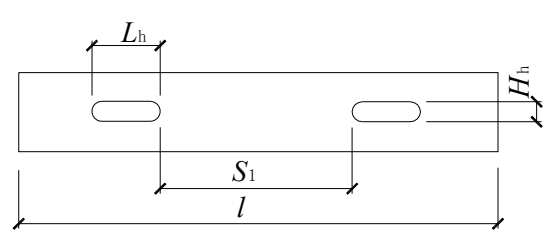

(c) Two holes in one column

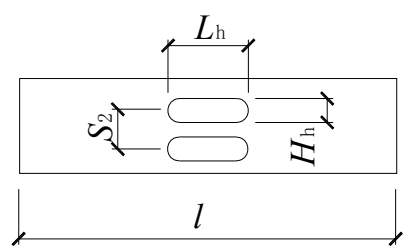

(b) Two holes in one row

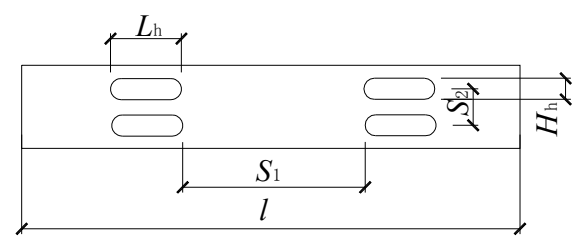

(d) Four holes in two rows and two columns

Fig. (2). Holes type of the web for specimens.

\subsection{Section Dimensions}

The dimensions and nomenclature for each specimen are presented in Fig. (3), and the measured value was recorded at the $1 / 4$ and $1 / 2$ length points for every specimen, so there were three measurement locations for each specimen. The measured mean values for specimens are summarized in Table 1 . The inside bend radius of specimens is $2 t$, where $t$ is the base thickness of members. The test specimens were labeled with characteristic information so that each column can be easily identified. For example, the label "AC-12-SH-1", where "AC" means axially-compressed member, "12" refers that the holes type is two holes in one row, "SH" means slotted hole, If a test was repeated, then a symbol of " 1 " was added which means different repeated group.

Table 1. Summary of measured specimen cross-section dimensions and yield stress.

\begin{tabular}{|c|c|c|c|c|c|c|c|c|c|c|c|}
\hline Specimens & $\begin{array}{c}\boldsymbol{l} \\
(\mathbf{m m})\end{array}$ & $\begin{array}{c}\boldsymbol{h}_{\mathbf{1}} \\
(\mathbf{m m})\end{array}$ & $\begin{array}{c}\boldsymbol{h}_{\mathbf{2}} \\
(\mathbf{m m})\end{array}$ & $\begin{array}{c}\boldsymbol{b}_{\mathbf{1}} \\
(\mathbf{m m})\end{array}$ & $\begin{array}{c}\boldsymbol{b}_{\mathbf{2}} \\
(\mathbf{m m})\end{array}$ & $\begin{array}{c}\boldsymbol{a}_{\mathbf{1}} \\
(\mathbf{m m})\end{array}$ & $\begin{array}{c}\boldsymbol{a}_{\mathbf{2}} \\
(\mathbf{m m})\end{array}$ & $\begin{array}{c}\boldsymbol{L}_{\mathbf{h}} \\
(\mathbf{m m})\end{array}$ & $\begin{array}{c}\boldsymbol{H}_{\mathbf{h}} \\
(\mathbf{m m})\end{array}$ & $\begin{array}{c}\boldsymbol{t} \\
(\mathbf{m m})\end{array}$ & $\begin{array}{c}\boldsymbol{F}_{\mathbf{y}} \\
(\mathbf{M P a})\end{array}$ \\
\hline AC-11-SH-1 & 803 & 99.94 & 99.80 & 37.85 & 37.56 & 12.11 & 11.65 & 25.41 & 14.62 & 1.4 & 295 \\
\hline AC-11-SH-2 & 800 & 99.87 & 100.01 & 37.64 & 37.98 & 12.51 & 11.75 & 24.89 & 13.99 & 1.46 & 295 \\
\hline AC-11SH-3 & 815 & 99.37 & 99.35 & 37.96 & 37.52 & 11.74 & 12.35 & 24.99 & 14.01 & 1.4 & 295 \\
\hline AC-11-SH-4 & 799 & 99.00 & 99.29 & 38.24 & 37.52 & 11.74 & 12.35 & 24.99 & 14.08 & 1.38 & 295 \\
\hline AC-11-SH-5 & 799 & 99.32 & 99.22 & 37.86 & 38.19 & 29.92 & 11.93 & 24.85 & 14.03 & 1.42 & 295 \\
\hline AC-11-SH-6 & 795 & 99.42 & 98.92 & 38.18 & 38.18 & 38.19 & 12.86 & 24.31 & 14.62 & 1.43 & 295 \\
\hline AC-21-SH-1 & 798 & 99.61 & 99.38 & 38.05 & 37.26 & 12.40 & 11.83 & 24.60 & 13.93 & 1.44 & 295 \\
\hline AC-21-SH-2 & 796 & 99.44 & 99.37 & 37.75 & 37.03 & 11.65 & 12.23 & 24.83 & 13.81 & 1.43 & 295 \\
\hline
\end{tabular}




\begin{tabular}{|c|c|c|c|c|c|c|c|c|c|c|c|}
\hline Specimens & $\begin{array}{c}l \\
(\mathbf{m m})\end{array}$ & $\begin{array}{c}h_{1} \\
(\mathrm{~mm})\end{array}$ & $\begin{array}{c}h_{2} \\
(\mathbf{m m})\end{array}$ & $\begin{array}{c}b_{1} \\
(\mathbf{m m})\end{array}$ & $\begin{array}{c}b_{2} \\
(\mathbf{m m})\end{array}$ & $\begin{array}{c}a_{1} \\
(\mathbf{m m})\end{array}$ & $\begin{array}{c}a_{2} \\
(\mathbf{m m})\end{array}$ & $\begin{array}{c}L_{\mathrm{h}} \\
(\mathbf{m m})\end{array}$ & $\begin{array}{c}H_{\mathrm{h}} \\
(\mathbf{m m})\end{array}$ & $\begin{array}{c}t \\
(\mathbf{m m})\end{array}$ & $\begin{array}{c}F_{\mathbf{y}} \\
(\mathbf{M P a})\end{array}$ \\
\hline AC-21-SH-3 & 809 & 99.38 & 99.37 & 37.23 & 37.69 & 11.66 & 12.33 & 25.20 & 13.97 & 1.45 & 295 \\
\hline AC-21-SH-4 & 796 & 99.08 & 99.36 & 37.69 & 37.44 & 11.88 & 12.22 & 24.88 & 14.43 & 1.41 & 295 \\
\hline AC-21-SH-5 & 795 & 99.40 & 99.25 & 37.34 & 37.72 & 11.87 & 12.41 & 24.80 & 14.39 & 1.43 & 295 \\
\hline AC-21-SH-6 & 798 & 99.31 & 99.55 & 37.85 & 37.38 & 12.54 & 11.72 & 24.83 & 14.08 & 1.41 & 295 \\
\hline AC-12-SH-1 & 795 & 100.68 & 100.05 & 37.79 & 38.14 & 11.96 & 12.12 & 24.91 & 14.07 & 1.44 & 295 \\
\hline AC-12-SH-2 & 796 & 99.38 & 99.10 & 37.60 & 38.12 & 12.47 & 11.93 & 24.89 & 13.65 & 1.45 & 295 \\
\hline AC-12-SH-3 & 798 & 99.20 & 99.03 & 38.12 & 37.66 & 12.08 & 12.21 & 24.99 & 14.01 & 1.42 & 295 \\
\hline AC-12-SH-4 & 794 & 99.28 & 98.43 & 37.58 & 38.00 & 11.88 & 12.56 & 24.89 & 14.14 & 1.4 & 295 \\
\hline AC-12-SH-5 & 795 & 99.23 & 99.37 & 37.75 & 37.90 & 12.54 & 11.80 & 24.94 & 13.97 & 1.45 & 295 \\
\hline AC-12-SH-6 & 796 & 100.29 & 100.07 & 38.05 & 37.96 & 13.60 & 10.47 & 24.92 & 14.15 & 1.44 & 295 \\
\hline AC-22-SH-1 & 797 & 98.96 & 98.97 & 36.85 & 37.62 & 11.72 & 11.98 & 23.72 & 15.11 & 1.44 & 295 \\
\hline AC-22-SH-2 & 797 & 99.48 & 99.52 & 37.42 & 37.57 & 11.51 & 12.79 & 23.06 & 15.20 & 1.43 & 295 \\
\hline AC-22-SH-3 & 798 & 99.48 & 99.39 & 37.87 & 37.31 & 12.32 & 11.85 & 23.61 & 15.12 & 1.48 & 295 \\
\hline AC-22-SH-4 & 806 & 99.89 & 99.52 & 37.86 & 37.73 & 12.15 & 11.78 & 23.60 & 15.28 & 1.49 & 295 \\
\hline AC-22-SH-5 & 797 & 99.20 & 99.61 & 37.67 & 38.29 & 12.00 & 12.40 & 22.70 & 15.33 & 1.45 & 295 \\
\hline AC-22-SH-6 & 806 & 100.06 & 99.81 & 38.00 & 37.93 & 13.58 & 10.44 & 23.35 & 14.70 & 1.48 & 295 \\
\hline AC-00-NH-1 & 802 & 99.87 & 99.85 & 38.22 & 37.59 & 12.39 & 13.16 & 1 & 1 & 1.47 & 295 \\
\hline AC-00-NH-2 & 800 & 99.78 & 99.84 & 38.17 & 37.31 & 13.44 & 11.75 & 1 & 1 & 1.46 & 295 \\
\hline
\end{tabular}

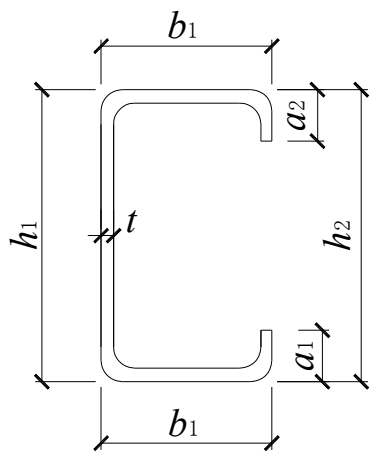

Fig. (3). Specimen measurement nomenclature.
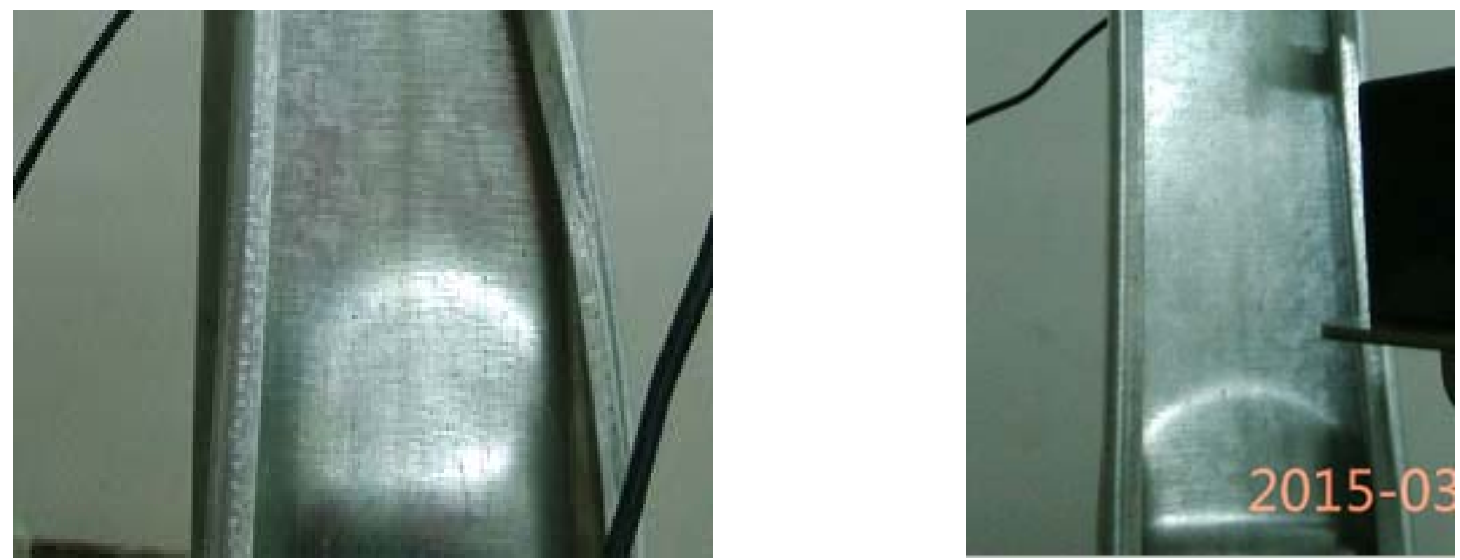

Fig. (4). Local buckling mode. 


\subsection{Material Properties}

Tension tests were carried out following the provisions of Metallic materials--Tensile testing--Part 1: Method of test at room temperature (GB/T228.1-2010) [18]. Six tensile coupons were cut from two ends of a test member including the web flat and two flanges flat. A $200 \mathrm{kN}$ capacity testing machine was used for applying loading. The mean value of six coupons test results is calculated. The specimen yield stress, $f_{\mathrm{y}}$, is $295 \mathrm{MPa}$, the steel elastic modulus, $E$, is assumed as $2.072 \times 10^{5} \mathrm{Mpa}$, and the elongation of the specimens is $31.85 \%$.

\section{EXPERIMENTAL RESULTS}

The failure modes of the specimens are depicted in Figs. (4-6). All columns exhibit the local buckling of the web near the supports (Fig.4), one distortional half-wave buckling along the length Fig. (5), and the global flexural buckling Fig. (6) after the peak load.

The tested ultimate strength for all specimens and the average ultimate strength for each test group are provided in Table 2. The comparison shows that there is a same influence on ultimate strength for specimens with one hole in one row and two holes in one column, as the reductions are $9.58 \%$ and $9.82 \%$, respectively, However, the reductions up to $14.02 \%$ and $16.81 \%$ for the specimens with two holes in one row and four holes in two columns, respectively. These test results indicate that the slotted web holes have a significant influence on ultimate strength and the influence increases with the increase of transverse area of holes.
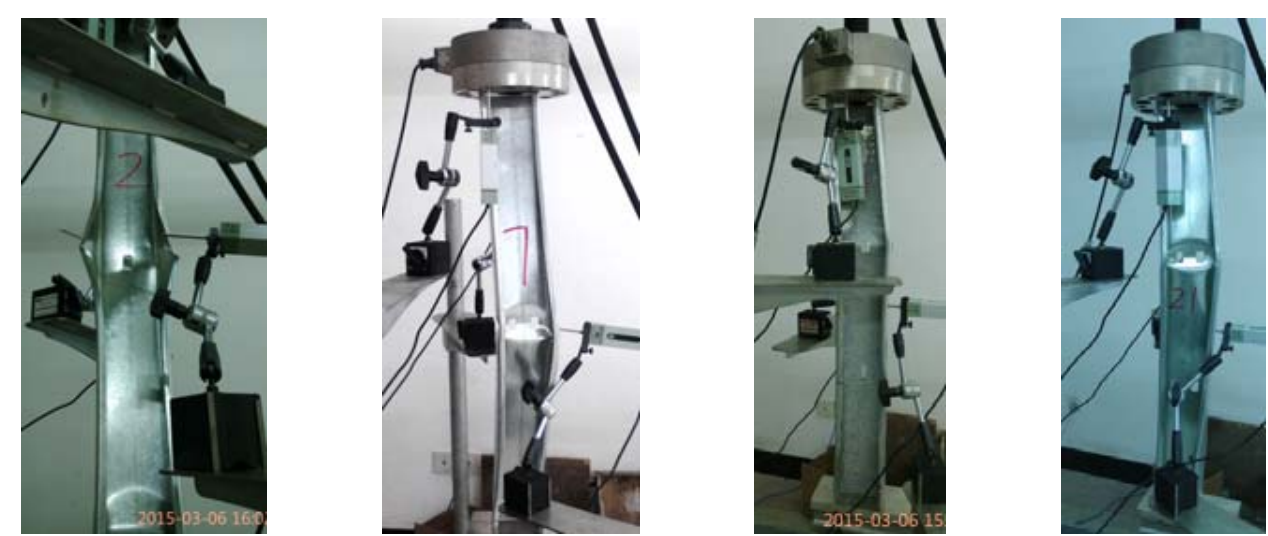

(a)One hole in one row (b) Two holes in one row (c) Two holes in one column (d) Four holes in two rows and two columns

Fig. (5). Distortional buckling mode.
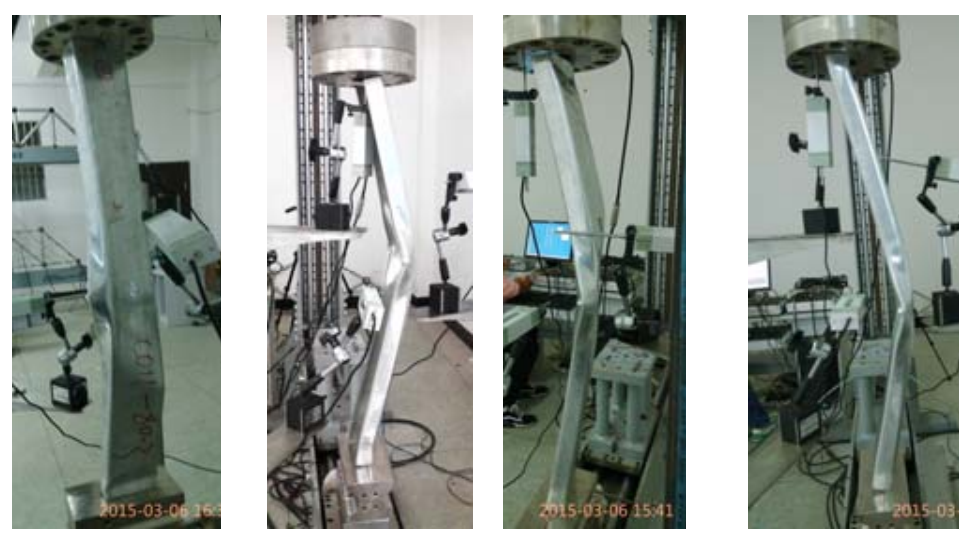

(a)One hole in one row (b) Two holes in one row (c) Two holes in one column (d) Four holes in two rows and two columns

Fig. (6). Global flexural buckling mode. 


\section{FINITE ELEMENT ANALYSIS}

\subsection{Finite Element Model}

The thin shell finite element non-linear analysis in ABAQUS was employed to simulate the experimental behavior of lipped channel compressed members with slotted web holes. At the two ends of the member, the fixed-fixed boundary condition was used.

Table 2. Comparison on tested ultimate strength of specimens.

\begin{tabular}{|c|c|c|c|}
\hline \multirow[b]{2}{*}{ Specimens } & \multirow[b]{2}{*}{ Tested Ultimate Strength $P_{t}(\mathrm{kN})$} & \multicolumn{2}{|c|}{ Statistic Analysis of $P_{t}$} \\
\hline & & $\begin{array}{c}\text { Mean value of } P_{\mathrm{t}} \\
(\mathrm{kN})\end{array}$ & Holes influence \\
\hline AC-11-SH-1 & 56.55 & \multirow{6}{*}{54.84} & \multirow{6}{*}{$9.58 \%$} \\
\hline AC-11-SH-2 & 54.90 & & \\
\hline AC-11SH-3 & 55.15 & & \\
\hline AC-11-SH-4 & 53.10 & & \\
\hline AC-11-SH-5 & 57.45 & & \\
\hline AC-11-SH-6 & 51.90 & & \\
\hline AC-21-SH-1 & 56.85 & \multirow{6}{*}{54.70} & \multirow{6}{*}{$9.82 \%$} \\
\hline AC-21-SH-2 & 55.40 & & \\
\hline AC-21-SH-3 & 56.85 & & \\
\hline AC-21-SH-4 & 52.75 & & \\
\hline AC-21-SH-5 & 52.50 & & \\
\hline AC-21-SH-6 & 53.85 & & \\
\hline AC-12-SH-1 & 51.45 & \multirow{6}{*}{52.15} & \multirow{6}{*}{$14.02 \%$} \\
\hline AC-12-SH-2 & 53.10 & & \\
\hline AC-12-SH-3 & 54.60 & & \\
\hline AC-12-SH-4 & 50.25 & & \\
\hline AC-12-SH-5 & 51.30 & & \\
\hline AC-12-SH-6 & 52.20 & & \\
\hline AC-22-SH-1 & 50.30 & \multirow{6}{*}{50.46} & \multirow{6}{*}{$16.81 \%$} \\
\hline AC-22-SH-2 & 48.95 & & \\
\hline AC-22-SH-3 & 51.20 & & \\
\hline AC-22-SH-4 & 52.05 & & \\
\hline AC-22-SH-5 & 49.85 & & \\
\hline AC-22-SH-6 & 50.40 & & \\
\hline AC-00-NH-1 & 61.03 & \multirow{2}{*}{60.66} & \multirow{2}{*}{ l } \\
\hline AC-00-NH-2 & 60.28 & & \\
\hline
\end{tabular}

The material model was based directly on the coupon tests. The ideal elastic-plastic curve was used based on the experimental steel elastic modular and yield stress which were the average values of the test results for simplifying finite element analysis. Residual stresses, residual strains and cold-work of forming effects were not included in the finite element model.

The ABAQUS S9R5 thin shell element was adopted to model compressed members with web holes. The element aspect ratio was kept below 3:1 along the length direction. In the cross-section, 6, 24, 2, and 2 elements were used for the flange, web, lip, and corner, respectively. The ABAQUS solution control employed was the modified Riks method and the arc length method.

Imperfection sensitivity was considered in the finite element analysis. The magnitudes of the geometric imperfections adopted were $L / 750$ according to Chinese cold-formed steel specification, where $L$ is the length of member. The shape of the geometric imperfection was obtained from the first buckling mode shape of the finite element Eigen buckling analysis. The finite element model for specimen and the mesh of the slotted web holes are depicted in (Fig. 7). 


\subsection{Elastic Buckling Analysis}

The critical elastic local buckling strength $\left(P_{\text {crl }}\right)$, distortional buckling strength $\left(P_{\text {crd }}\right)$, and ultimate yield strength $\left(P_{\mathrm{y}}\right)$ are provided in Table 3 for compressed columns with different hole types and without hole. The nominal dimensions are used in the Eigen-value elastic buckling analysis.

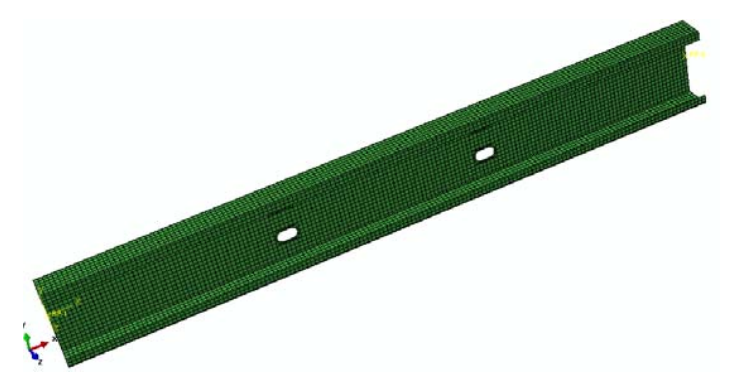

(a) Column model

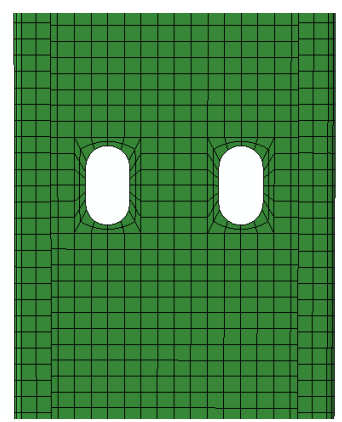

(b) Mesh of the slotted web holes

Fig. (7). Finite element model.
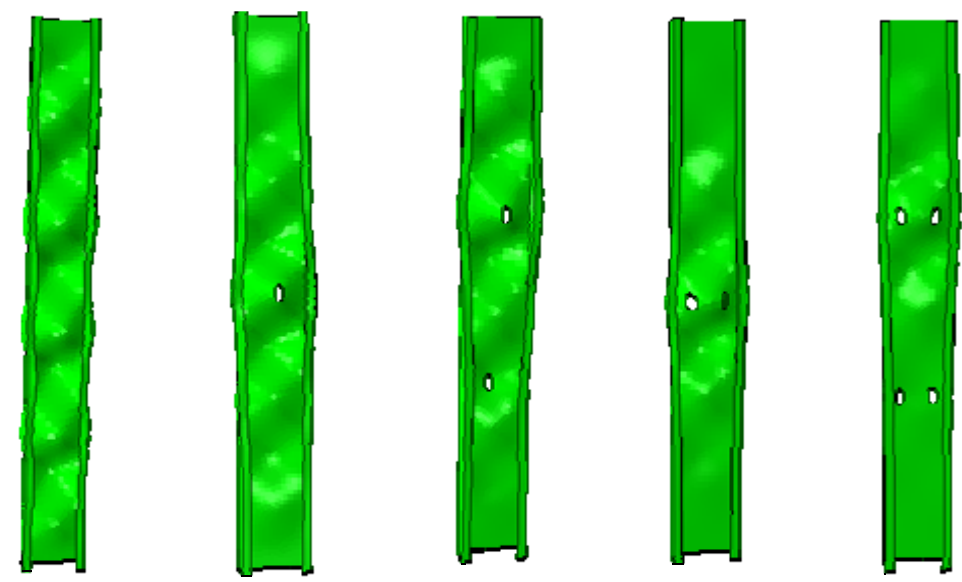

Fig. (8). Comparison on local buckling mode.

The comparison in Table 3 illustrates that the slotted web hole has a little influence on elastic local buckling strength for axially compressed columns, but the effect is not significant because the ratio of the width of hole to the width of web is 0.14 approximately. Because the local buckling occur mainly at the proximity of holes for members with larger cross-sectional area of holes as shown in Fig. (8), the elastic buckling strengths of AC-12-SH and AC-22$\mathrm{SH}$ are higher than AC-11-SH and AC-21-SH. However, the slotted web holes have a significant influence on elastic distortional buckling strength of axially compressed columns, especially for columns with wider web holes crosssectional area. The elastic distortional buckling strengths of AC-11-SH and AC-21-SH are higher than AC-12-SH and 
AC-22-SH because the web with wider holes area has lower torsional stiffness for flange.

The first local buckling and distortional buckling shapes for axially-compressed columns with different hole types and without hole are compared in (Figs. 8 and $\mathbf{9}$ ).
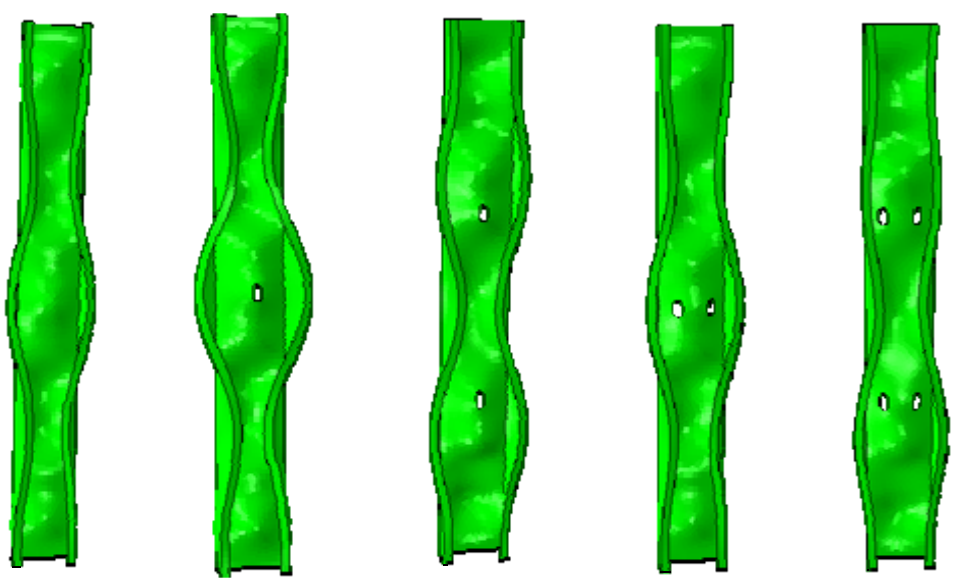

Fig. (9). Comparison on distortional buckling mode.

The comparisons in Figs. (8 and 9) illustrate that the web holes have no significant effect on elastic local and distortional buckling half-wave length when the ratio of the width of hole is very small for the axially compressed columns, but the deformation of cross section located at the holes of column is bigger than that of other cross sections.

Table 3. Comparison on critical elastic buckling strength.

\begin{tabular}{|c|c|c|c|c|}
\hline Hole type & $\boldsymbol{L}(\mathbf{m m})$ & $\boldsymbol{P}_{\mathbf{y}}(\mathbf{k N})$ & $\boldsymbol{P}_{\text {crr }}(\mathbf{k N})$ & $\boldsymbol{P}_{\text {crd }}(\mathbf{k N})$ \\
\hline AC-11-SH & 800 & 88.5 & 67.34 & 83.65 \\
\hline AC-21-SH & 800 & 88.5 & 67.11 & 79.34 \\
\hline AC-12-SH & 800 & 88.5 & 69.86 & 63.86 \\
\hline AC-22-SH & 800 & 88.5 & 70.79 & 63.79 \\
\hline AC-00-NH & 800 & 88.5 & 71.23 & 95.29 \\
\hline
\end{tabular}
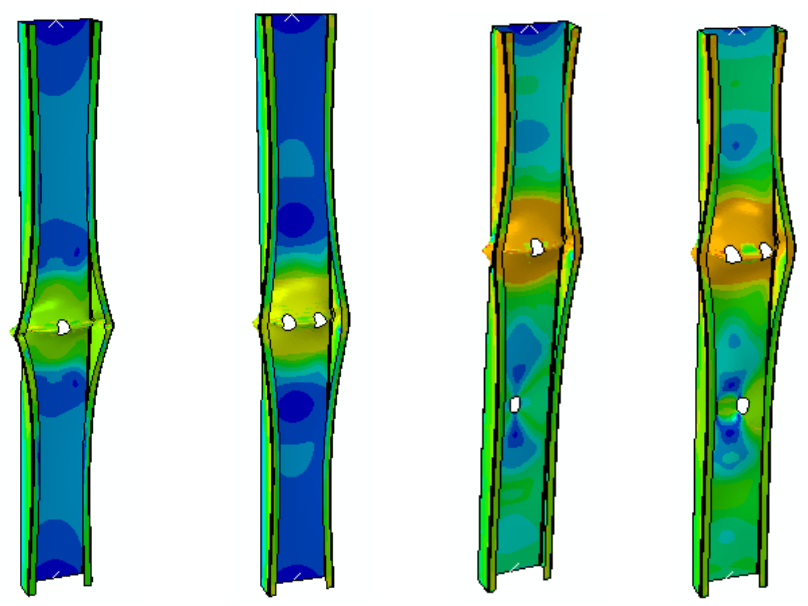

(a) One hole in one row (b) Two holes in one row (c) Two holes in one column (d) Four holes in two rows and two columns

Fig. (10). Failure modes of columns with slotted holes. 


\subsection{Failure Mode and Capacity}

The buckling modes for the typical specimens obtained by the FEM are presented in Fig. (10), which is agreed to the test failure modes depicted in Figs. (4 and 5) The local and distortional buckling can occur for the columns with slotted web holes. This observation suggests that the FE model can model the buckling mode of columns with slotted holes.

The ultimate compressed capacities $\left(P_{\mathrm{ABA}}\right)$ obtained from the FEM are compared with the experimental ultimate capacities $\left(P_{\mathrm{t}}\right)$ as shown in Table 4 for each specimen. The mean value of the FEM-to-experimental ultimate compressed capacities ratio is 1.0172 with the corresponding coefficient of variation of 0.015 for all compressed specimens. The comparisons of the ultimate capacities demonstrate that the ultimate compressed capacities obtained from the FEM are close to the experimental ultimate capacities and the FE model can also predict the ultimate compressed capacity.

Table 4. Comparison on ultimate capacities between test results and calculated results.

\begin{tabular}{|c|c|c|c|c|c|c|c|c|c|c|c|c|c|}
\hline Specimens & $\begin{array}{c}P_{\mathrm{t}} \\
(\mathrm{kN})\end{array}$ & $\begin{array}{l}P_{A B A} \\
(\mathbf{k N})\end{array}$ & $\begin{array}{c}P_{\mathrm{C} 1} \\
(\mathbf{k N})\end{array}$ & $\begin{array}{c}P_{\mathrm{C} 2} \\
(\mathrm{kN})\end{array}$ & $\begin{array}{c}P \mathbf{s}_{1} \\
(\mathbf{k N})\end{array}$ & $\begin{array}{c}P \mathbf{s}_{2} \\
(\mathrm{kN})\end{array}$ & $\begin{array}{c}P_{N} \\
(\mathbf{k N})\end{array}$ & $\boldsymbol{P}_{A B A} / \boldsymbol{P}_{\mathrm{t}}$ & $\boldsymbol{P}_{\mathrm{Cl}} / \boldsymbol{P}_{\mathrm{t}}$ & $\boldsymbol{P}_{\mathrm{C} 2} / \boldsymbol{P}_{\mathrm{t}}$ & $P \mathrm{~s}_{1} / P_{\mathrm{t}}$ & $P \mathbf{s}_{2} / P_{\mathrm{t}}$ & $\boldsymbol{P}_{N} / \boldsymbol{P}_{\mathrm{t}}$ \\
\hline AC-11-SH-1 & 56.55 & 56.22 & 51.98 & 54.31 & 49.12 & 51.44 & 50.89 & 0.99 & 0.92 & 0.96 & 0.87 & 0.91 & 0.90 \\
\hline AC-11-SH-2 & 54.90 & 55.12 & 55.69 & 58.02 & 52.51 & 54.98 & 54.21 & 1.00 & 1.01 & 1.06 & 0.96 & 1.00 & 0.99 \\
\hline AC-11SH-3 & 55.15 & 55.71 & 52.00 & 54.34 & 49.20 & 51.46 & 51.03 & 1.01 & 0.94 & 0.99 & 0.89 & 0.93 & 0.93 \\
\hline AC-11-SH-4 & 53.10 & 53.85 & 50.98 & 53.33 & 48.21 & 50.38 & 50.28 & 1.01 & 0.96 & 1.00 & 0.91 & 0.95 & 0.95 \\
\hline AC-11-SH-5 & 57.45 & 58.01 & 53.28 & 55.56 & 51.11 & 53.35 & 53.42 & 1.01 & 0.93 & 0.97 & 0.89 & 0.93 & 0.93 \\
\hline AC-11-SH-6 & 51.90 & 53.36 & 53.71 & 55.89 & 50.56 & 52.79 & 52.34 & 1.03 & 1.03 & 1.08 & 0.97 & 1.02 & 1.01 \\
\hline AC-21-SH-1 & 56.85 & 58.99 & 54.43 & 56.76 & 51.28 & 53.68 & 52.94 & 1.04 & 0.96 & 1.00 & 0.90 & 0.94 & 0.93 \\
\hline AC-21-SH-2 & 55.40 & 55.18 & 53.62 & 55.94 & 50.44 & 52.87 & 51.96 & 1.00 & 0.97 & 1.01 & 0.91 & 0.95 & 0.94 \\
\hline AC-21-SH-3 & 56.85 & 56.98 & 54.78 & 57.08 & 51.46 & 53.92 & 52.98 & 1.00 & 0.96 & 1.00 & 0.91 & 0.95 & 0.93 \\
\hline AC-21-SH-4 & 52.75 & 53.18 & 52.60 & 54.94 & 49.52 & 51.84 & 51.25 & 1.01 & 1.00 & 1.04 & 0.94 & 0.98 & 0.97 \\
\hline AC-21-SH-5 & 52.50 & 54.18 & 53.81 & 56.15 & 50.63 & 53.02 & 52.24 & 1.03 & 1.02 & 1.07 & 0.96 & 1.01 & 1.00 \\
\hline AC-21-SH-6 & 53.85 & 53.47 & 52.67 & 55.03 & 49.51 & 51.84 & 51.28 & 0.99 & 0.98 & 1.02 & 0.92 & 0.96 & 0.95 \\
\hline AC-12-SH-1 & 51.45 & 52.74 & 54.57 & 56.92 & 43.46 & 45.88 & 48.17 & 1.03 & 1.06 & 1.11 & 0.84 & 0.89 & 0.94 \\
\hline AC-12-SH-2 & 53.10 & 54.02 & 55.15 & 57.47 & 43.58 & 45.94 & 48.55 & 1.02 & 1.04 & 1.08 & 0.82 & 0.87 & 0.91 \\
\hline AC-12-SH-3 & 54.60 & 55.23 & 53.36 & 55.69 & 42.39 & 44.65 & 48.15 & 1.01 & 0.98 & 1.02 & 0.78 & 0.82 & 0.88 \\
\hline AC-12-SH-4 & 50.25 & 52.00 & 52.21 & 54.57 & 41.59 & 43.80 & 46.50 & 1.03 & 1.04 & 1.09 & 0.83 & 0.87 & 0.93 \\
\hline AC-12-SH-5 & 51.30 & 51.97 & 55.12 & 57.44 & 43.56 & 45.93 & 48.46 & 1.01 & 1.07 & 1.12 & 0.85 & 0.90 & 0.94 \\
\hline AC-12-SH-6 & 52.20 & 53.13 & 54.57 & 56.92 & 43.43 & 45.82 & 48.14 & 1.02 & 1.05 & 1.09 & 0.83 & 0.88 & 0.92 \\
\hline AC-22-SH-1 & 50.30 & 53.29 & 54.06 & 56.32 & 42.45 & 44.90 & 47.07 & 1.06 & 1.07 & 1.12 & 0.84 & 0.89 & 0.94 \\
\hline AC-22-SH-2 & 48.95 & 50.11 & 53.80 & 56.16 & 42.64 & 45.05 & 47.27 & 1.02 & 1.10 & 1.15 & 0.87 & 0.92 & 0.97 \\
\hline AC-22-SH-3 & 51.20 & 52.68 & 56.73 & 59.01 & 44.49 & 47.01 & 49.24 & 1.03 & 1.11 & 1.15 & 0.87 & 0.92 & 0.96 \\
\hline AC-22-SH-4 & 52.05 & 53.23 & 57.31 & 59.56 & 44.93 & 47.46 & 49.85 & 1.02 & 1.10 & 1.14 & 0.86 & 0.91 & 0.96 \\
\hline AC-22-SH-5 & 49.85 & 50.48 & 55.20 & 57.53 & 43.70 & 46.04 & 48.56 & 1.01 & 1.11 & 1.15 & 0.88 & 0.92 & 0.97 \\
\hline AC-22-SH-6 & 50.40 & 51.22 & 56.83 & 59.10 & 44.76 & 47.24 & 49.49 & 1.02 & 1.13 & 1.17 & 0.89 & 0.94 & 0.98 \\
\hline AC-00-NH-1 & 61.03 & 63.01 & 56.45 & 58.74 & 56.45 & 58.74 & 57.98 & 1.03 & 0.92 & 0.96 & 0.92 & 0.96 & 0.95 \\
\hline AC-00-NH-2 & 60.28 & 62.74 & 55.97 & 58.27 & 55.97 & 58.27 & 57.61 & 1.04 & 0.93 & 0.97 & 0.93 & 0.97 & 0.96 \\
\hline \multicolumn{8}{|c|}{ Mean value } & 1.0187 & 1.0152 & 1.0585 & 0.8863 & 0.9305 & 0.9471 \\
\hline \multicolumn{8}{|c|}{ Variance } & 0.0156 & 0.0657 & 0.0678 & 0.0476 & 0.0469 & 0.0292 \\
\hline \multicolumn{8}{|c|}{ Coefficient of variation } & 0.0153 & 0.0647 & 0.0640 & 0.0537 & 0.0504 & 0.0308 \\
\hline
\end{tabular}

The load-compressed deformation curves for different holes analyzed using finite element method are illustrated in Fig. (11), where the cross-sectional dimensions of columns are the nominal section dimensions. As shown in Fig. (11), the holes have no effect on the stiffener of columns with slotted web holes because the local buckling occurs at the end of the column and the distortional buckling approaches near to the global flexural buckling. But the holes can decrease the load-carrying capacities.

\subsection{Effect of the Multiple Holes}

The Mises stress graph and load-compressed deformation curves of columns with different holes dimension are shown in Figs. (12 and 13). The height of holes is $50 \mathrm{~mm}$ and the total transverse width of holes is $50 \mathrm{~mm}$,but the space 
of holes is different. For example, as shown in Fig. (12a), the width of holes is $10 \mathrm{~mm}$, the space of holes is $30 \mathrm{~mm}$ because the total width of holes is $50 \mathrm{~mm}$. As shown in Fig. (12), the distortional buckling occurs for all columns and the maximum stress occurs at the middle height. As shown in Fig. (13), the width of single hole has less effect on ultimate strength if the total width of all transverse holes of column is same. So the ultimate strength of column with multiple transverse holes approximates to equal to the ultimate strength of column with single hole which has the same transverse width to the multiple holes. The multiple holes have a little effect on the stiffeness of column with slotted web holes. The wider the net width of whole holes is, the lower the stiffeness of axially-compressed column is.

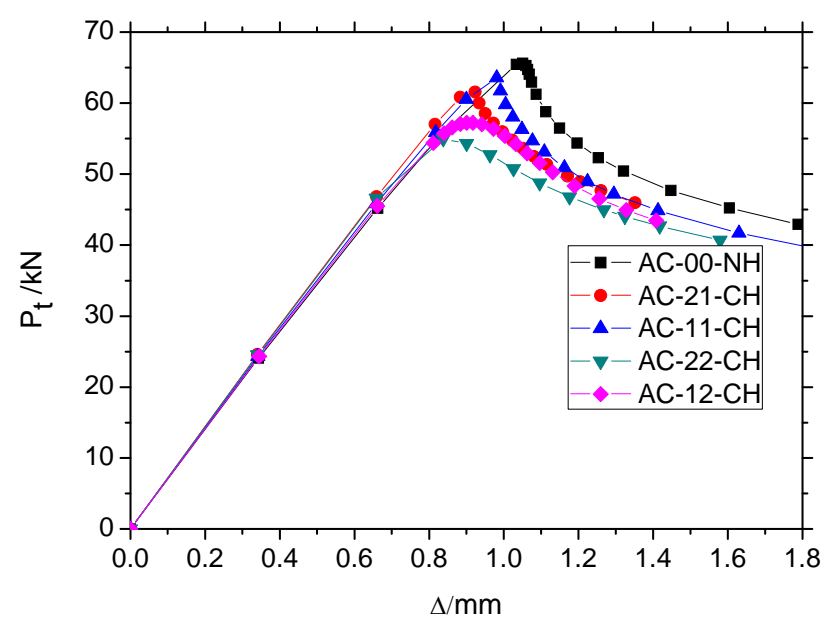

Fig. (11). Load- compressed deformation curves for columns with different holes in nominal dimension.

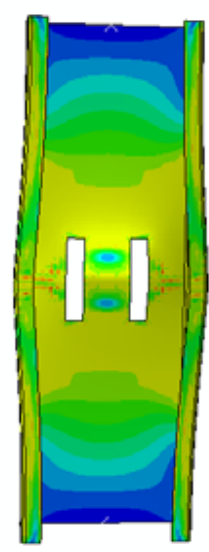
(a) $\mathrm{H}_{\text {hole }}=10$
(b) $\mathrm{H}_{\text {hole }}=15$
(c) $\mathrm{H}_{\text {hole }}=20$
(d) $\mathrm{H}_{\text {hole }}=25\left(\right.$ single hole $\left.\mathrm{H}_{\text {hole }}=50\right)$
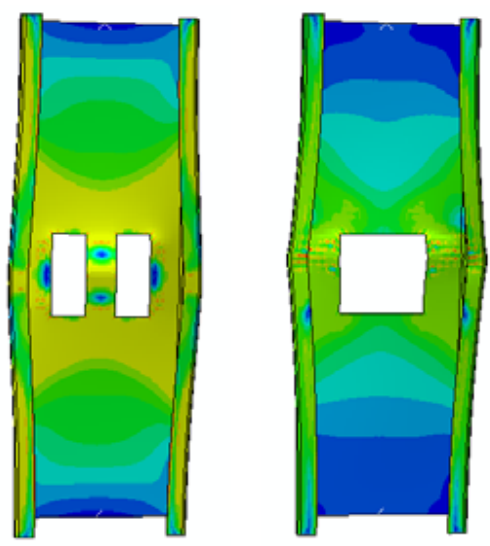

Fig. (12). Mises stress graph of columns with different width of single hole.

\section{PROPOSED DESIGN METHOD}

\subsection{Comparison on Ultimate Capacity}

Two calculated method are used to predict the ultimate capacity of each specimen and evaluate every design method: (1) The Chinese cold-formed steel specification GB5018-2002, (2) The North America cold-formed steel specification AISI-S100 (2016).

The ultimate capacities of every specimen calculated using Chinese cold-formed steel specification and North America cold-formed steel specification are provided in Table 4, including ratios of predicted-to-test capacities of each 
specimen for two design methods, Where $P_{\mathrm{CI}}$ and $P_{\mathrm{C}}$ are the ultimate capacity predicted using Chinese cold-formed steel specification considering the interaction of the elements and without considering the interaction of the elements, $\mathrm{P}_{\mathrm{N}}$ is the calculated results using North America cold-formed steel specification.

The mean values of the ratios of calculated compressive capacities to test results $P_{\mathrm{CI}}$ and $P_{\mathrm{C}}$ obtained using Chinese specification considering the interaction of the elements and without considering the interaction of the elements are 1.0225 and 1.0663, respectively. The comparison results indicate that the current Chinese cold-formed steel specification is not safe to predict the ultimate capacity of column with slotted web holes because the code doesn't consider the effect of the holes. So the proposed method for predicting the ultimate capacity of compressed column with slotted web holes should be analyzed and put forward based on the Chinese cold-formed steel specification.

However the mean value of the ratios of calculated compressive capacities to test results using North America coldformed steel specification is 0.9466 with the corresponding coefficient of variation of 0.0321 for columns with holes. The comparison demonstrates that North America cold-formed steel specification takes into account the effect of slotted web holes and is conservative.

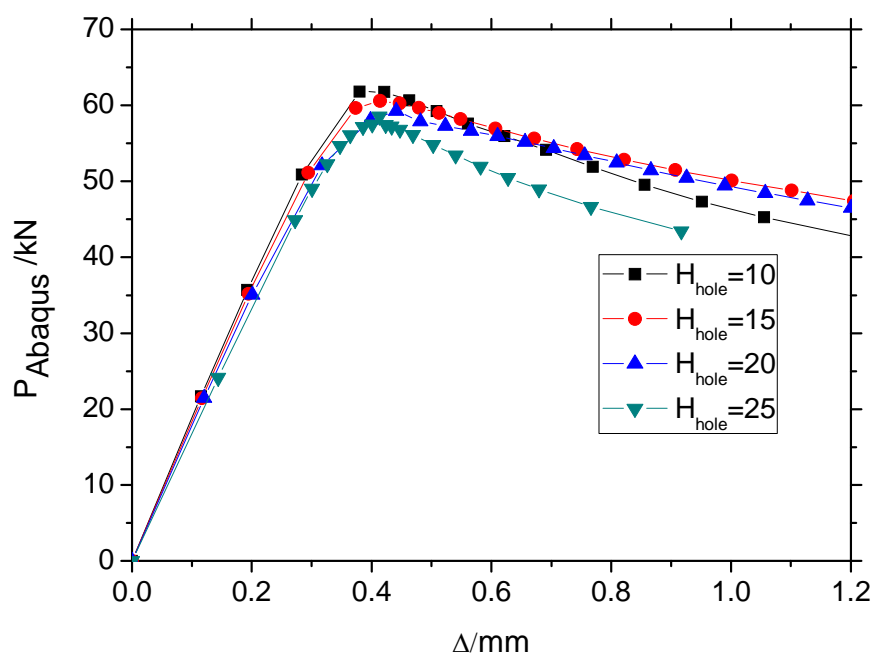

Fig. (13). Load-compressed deformation curves of columns with different width of single hole.

\subsection{Proposed Design Method}

The model proposal should be investigated based on the existing EWM in Chinese cold-formed steel specification in order to consider the reduction of capacity because of the influence of slotted web holes of axially compressed columns.

The effective width of the web with slotted holes proposed for Chinese cold-formed steel specification can be determined using Eq.1 based on Chinese cold-formed steel specification and calculated method for the effective width of the element with slotted holes in North America cold-formed steel specification when the compressive strength of columns with the slotted web holes are calculated.

$$
b_{e}=\min \left(b_{e n h}, b_{e h}\right)
$$

Where $b_{\text {enh }}$ is the effective width of the web without considering the influence of the slotted holes, and $b_{\text {eh }}$ is the effective width of the web considering the influence of slotted holes.

$b_{\text {enh }}$ is calculated using Eq. 2 based on Chinese cold-formed steel specification. 


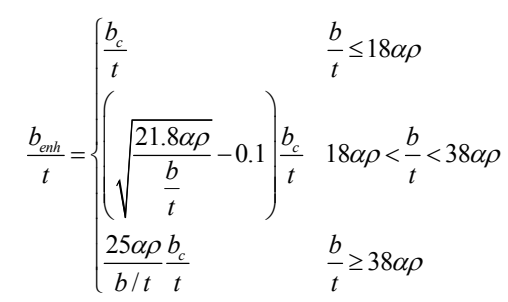

where $b$ and $t$ are the width and thickness of the element, respectively; $\alpha$ is a coefficient, and $\alpha=1.15-0.15 \psi, \psi$ is an uneven coefficient of the compression stress distribution (for axially-compressive members, $\psi=1$ ); $b_{\mathrm{c}}$ is the compressive width of the plate; $\rho$ is a calculating coefficient, $\rho=\sqrt{235 k k_{1} / f_{y}} k_{1}$ is the interaction coefficient due to the adjacent element, $k_{1}$ equals to 1 when the interaction effect of plates is ignored, $k$ is the stability coefficient of the element under compression, $k$ equals 4 for the web of the axially compressed members when the influence of slotted holes is not considered.

$b_{\text {eh }}$ is estimated using Eq.2 based on Chinese cold-formed steel specification, but the plates adjacent to the slotted hole or multiple slotted holes are as the unstiffened strip and $k$ of the unstiffened strip should be calculated using Eq. 3 when the influence of slotted holes is considered [11] refer to the North America cold-formed steel specification.

$$
k=\left\{\begin{array}{cc}
0.425+\frac{0.2}{\left(L_{h} / b_{u}\right)^{0.95}-0.6} & L_{h} / b_{u} \geq 1 \\
0.925 & L_{h} / b_{u}<1
\end{array}\right.
$$

Where $L_{\mathrm{h}}$ and $b_{\mathrm{u}}$ are the length of slotted hole and the width of unstiffened strip.

Meanwhile, the effective width of web with slotted holes should be less than the net section width of web as Eq.4.

$$
b_{e} \leq b-b_{h}
$$

Where $b_{\mathrm{h}}$ is the total width of the slotted holes.

The ultimate capacities of each specimen calculated using proposed method are provided in Table (4), $\mathrm{P}_{\mathrm{S} 1}$ and $\mathrm{P}_{\mathrm{S} 2}$ are the ultimate capacity calculated using proposed method considering the interaction of the plates and without considering the interaction of the plates, respectively. The mean values of ratios of predicted results $\mathrm{P}_{\mathrm{S} 1}$ and $\mathrm{P}_{\mathrm{S} 2} \mathrm{using}$ the proposed method to test results are 0.883 and 0.9277 with the corresponding coefficient of variation of 0.0545 and 0.0514 , respectively. The comparisons indicate that the proposed method is conservative and can be used to calculate the ultimate capacity of the specific compressive column with slotted web holes studied in this paper.

\section{CONCLUSION}

The following conclusions can be attained according to the experimental and analytical research of 26 axially compressed columns with or without slotted web holes.

1. The compressive test results on cold-formed lipped channel sections with slotted web holes have shown that the intermediate length columns display the distortional buckling and failure with interaction of local, distortional, and global flexural buckling. The slotted web holes can decrease the ultimate load of compressive columns. The reduction increases with the increase of cross-sectional area of holes.

2. The failure modes and ultimate capacities obtained from the FEM are close to test results. These comparisons indicate that the finite element model can analyze the buckling failures mode and ultimate capacities of coldformed steel members with slotted web holes. The web slotted hole has a small influence on elastic buckling mode, buckling half-wavelength, and elastic local buckling strength of compressive column, but has a significant influence on elastic distortional buckling strength. The ultimate strength of column with multiple transverse holes approximates to equal the ultimate strength of column with single hole which has the same transverse width to the multiple holes. 
3. Modifications about the effective width method based on the current Chinese specification have been proposed. Comparisons between predicted results using proposed method and test results demonstrate that the proposed method provides an accurate and reliable design method for the specific cold-formed steel lipped channel compressive columns with slotted web holes studied in this paper.

\section{ETHICS APPROVAL AND CONSENT TO PARTICIPATE}

Not applicable.

\section{HUMAN AND ANIMAL RIGHTS}

No Animals/Humans were used for studies that are base of this research.

\section{CONSENT FOR PUBLICATION}

Not applicable.

\section{CONFLICT OF INTEREST}

The authors confirm that this article content has no conflict of interest.

\section{ACKNOWLEDGEMENTS}

The author gratefully acknowledgements the financial support provided by Department of Science and Technology Natural Science Foundation Projects of Jiangxi Province in China (No: 20151BAB206055), National Natural Science Foundation Projects of China (No: 51308277), and China Postdoctoral Science Foundation funded project (No: 2016M590382). Author really appreciates the professor Schafer B.W. in Johns Hopkins University who provided the suggestion and guidance.

\section{REFERENCES}

[1] C.D. Moen, Direct strength design for cold-formed steel members with perforations., Johns Hopkins University: Baltimore, USA, 2008.

[2] R.A. Ortiz-Colberg, The load carrying capacity of perforated coldformed steel columns., Cornell University: NY, USA, 1981.

[3] N. Abdel-Rahman, Cold-formed steel compression members with perforations., McMaster University: Ontario, USA, 1997.

[4] A.S. Banwait, Axial load behaviour of thin-walled steel sections with openings., McMaster University: Ontario, USA, 1987.

[5] K.S. Sivakumaran, "Load capacity of uniformly compressed cold-formed steel section with punched web", Can. J. Civ. Eng., vol. 14, no. 4, pp. 550-558, 1987.

[http://dx.doi.org/10.1139/187-080]

[6] R. Loov, "Local buckling capacity of C-shaped cold-formed steel sections with punched webs", Can. J. Civ. Eng., vol. 11, no. 1, pp. 1-7, 1984.

[http://dx.doi.org/10.1139/184-001]

[7] Y. Pu, M.H. Godley, and R.G. Beale, "Prediction of ultimate capacity of perforated lipped channels", Journal Structure Engineering-ASCE., vol. 125 , no. 15 , pp. 510-514, 1999.

[8] J. Rhodes, and F.D. Schneider, "The compressional behavior of perforated elements", , pp. 11-18 Twelfth international specialty conference on cold-formed steel structures: recent research and developments in cold-formed steel design and construction., Saint Louis: University of Missouri-Rolla, USA

[9] "America Iron and Steel Institute", In: North American specification for the design of cold-formed steel structural elements, AISI-S100-2016: Washington, D.C, 2016.

[10] C.D. Moen, and B.W. Schafer, "Elastic buckling of thin plates with holes in compression or bending", Thin-walled Struct., vol. 47, pp. 1597-1607, 2009. [http://dx.doi.org/10.1016/j.tws.2009.05.001]

[11] C.D. Moen, and B.W. Schafer, "Elastic buckling of cold-formed steel columns and beams with holes", Eng. Struct., vol. 31, no. 12, pp. 2812-2824, 2009. [http://dx.doi.org/10.1016/j.engstruct.2009.07.007]

[12] C.D. Moen, and B.W. Schafer, "Experiments on cold-formed steel columns with holes", Thin-walled Struct., vol. 46, pp. 1164-1182, 2008. [http://dx.doi.org/10.1016/j.tws.2008.01.021]

[13] C.D. Moen, and B.W. Schafer, "Direct strength method for design of cold-formed steel columns with holes", J. Struct. Eng., vol. 137, no. 5, pp. 559-570, 2012.

[http://dx.doi.org/10.1061/(ASCE)ST.1943-541X.0000310] 
[14] B. He, and T. Zhou, "Local buckling of cold-formed steel sections and a unified approach for calculating effective width in AISI specification", Progressing Steel Building Structures, vol. 7, no. 4, pp. 6-10, 2005. [in Chinese].

[15] J. Zhou, and S. Yu, "Equivalent calculation of buckling stress for cold-formed thin wall perforated channel column", Steel Construction, vol. 25, no. 2, pp. 27-31, 2010. [in Chinese].

[16] S. Wen, "Flexural-torsional buckling of axially loaded columns with perforated cold formed thin-walled section", Journal of Civil Engineering, vol. 29, no. 1, pp. 72-79, 1996. [in Chinese].

[17] “Technical code of cold-formed thin-wall steel structures”, GB50018-2002., China Planning Press: Beijing, 2002. [in Chinese]

[18] “Metallic materials--Tensile testing--Part 1: Method of test at room temperature”, GB/T228.1-2010., China Standard Press: Beijing, 2010. [in Chinese]

(C) 2017 Xingyou Yao.

This is an open access article distributed under the terms of the Creative Commons Attribution 4.0 International Public License (CC-BY 4.0), a copy of which is available at: https://creativecommons.org/licenses/by/4.0/legalcode. This license permits unrestricted use, distribution, and reproduction in any medium, provided the original author and source are credited. 